\title{
Pembelajaran Computational Thinking untuk Siswa SMA Institut Indonesia Semarang
}

\author{
Erwin Yudi Hidayat ${ }^{1}$, Affandy $^{2}$, Ayu Pertiwi $^{3}$ \\ ${ }^{1,2,3}$ Fakultas Ilmu Komputer, Universitas Dian Nuswantoro, Semarang \\ E-mail: ${ }^{2}$ erwin@dsn.dinus.ac.id, ${ }^{2}$ affandy@dsn.dinus.ac.id, ${ }^{3}$ ayu.pertiwi@ dsn.dinus.ac.id
}

\begin{abstract}
Abstrak
Pembelajaran mengenai teknologi informasi telah banyak dilakukan di pendidikan menengah atas untuk mempersiapkan peserta didik menghadapi perkembangan teknologi informasi. Penerapan teknologi informasi di berbagai bidang sesungguhnya memerlukan kemampuan berpikir komputasional yang menjadi populer dalam beberapa tahun terakhir ini menjadi kemampuan yang mendasar yang seyogyanya dimiliki oleh setiap insan dalam era digital ini. Kemampuan berpikir komputasional adalah proses berpikir dalam melakukan formulasi persoalan dan solusinya sehingga solusi dapat dinyatakan dalam suatu bentuk yang dapat dikerjakan secara efektif oleh manusia atau mesin. Berpikir komputasional adalah kemampuan dasar yang diperlukan setiap orang, bukan hanya ilmuwan komputer. Selain kemampuan membaca, menulis, dan aritmatika, kita juga perlu menambahkan kemampuan berpikir komputasional kepada seorang anak untuk mengasah kemampuan analisisnya.
\end{abstract}

Kata kunci: computational thinking, bebras, problem solving

\begin{abstract}
Learning about information technology has been widely carried out in senior secondary education to prepare students for information technology developments. The application of information technology in various fields actually requires the ability to computational thinking that has become popular in recent years become a fundamental ability that should be possessed by every human being in this digital age. Computational thinking ability is the process of thinking in formulating problems and their solutions so that solutions can be expressed in a form that can be done effectively by humans or machines. Computational thinking is a basic skill that everyone needs, not just computer scientists. In addition to reading, writing and arithmetic skills, we also need to add computational thinking skills to a child to hone his analytical skills.
\end{abstract}

Keywords: computational thinking, bebras, problem solving

\section{PENDAHULUAN}

Dalam kehidupannya, manusia dihadapkan pada situasi yang sering bertentangan, yang disebut dengan masalah. Masalah adalah kesenjangan antara apa yang terjadi dengan segala hal dan apa yang seharusnya terjadi dengan hal tersebut [1]. Banyak pula yang mendefinisikan masalah sebagai suatu kondisi sulit yang membutuhkan solusi, jalan keluar atau pemecahan. Sebab, apabila suatu masalah dibiarkan, dapat memperburuk keadaan seseorang atau orang lain.

Munculnya masalah dapat disebabkan oleh tindakan dan pola pikir manusia. Tidaklah sama, masalah yang dihadapi tiap-tiap orang, termasuk bagaimana cara menyelesaikannya. Jika masalah tersebut dapat ditemukan solusinya, akan mempermudah urusan. Hanya saja, tak jarang justru kegagalan yang didapati. Akibatnya, masalah yang dihadapi akan menjadi semakin rumit. 
Pada proses tumbuh kembang, remaja memiliki tugas perkembangan yang terpusat pada perubahan sikap dan pola perilaku. Batas yang dapat digunakan sebagai patokan antara masa awal remaja dan akhir remaja terletak kira-kira di sekitar usia tujuh belas tahun [2]. Seorang siswa yang sedang mengalami sebuah permasalahan dapat menghambat proses belajar. Usia remaja adalah usia yang paling kritis dalam kehidupan seseorang, rentang usia peralihan dari masa kanak-kanak menuju remaja dan akan menentukan kematangan usia dewasa [3].

Dalam kehidupan sehari-hari, siswa sering menghadapi berbagai masalah. Baik masalah sewaktu bermain, saat membantu ibu membersihkan rumah, saat berbelanja, pergi ke kebun, menunggu adik, atau sejumlah kegiatan sehari-hari siswa lainnya. Biasanya, siswa memecahkan masalah itu dengan cara trial and error (coba-coba). Sehingga siswa sering memerlukan waktu lama untuk menyelesaikannya bahkan kadangkala siswa merasa putus asa berkepanjangan karena tidak mampu menyelesaikannya. Kalau siswa sering putus asa ketika tidak mampu menyelesaikan beberapa permasalahan yang dihadapinya, berarti situasi itu melatih siswa untuk menumbuhkan sikap negatif dan cepat putus asa [1].

Metode pembelajaran dengan pendekatan problem solving, merupakan sebuah jalan melatih peserta didik dalam menghadapi berbagai masalah baik itu secara individu ataupun masalah kelompok, untuk dipecahkan sendiri dan atau bersama-sama. Investigasi dan penemuan adalah orientasi yang terdapat dalam pembelajaran prolem solving, yang pada dasarnya adalah fokus terhadap pemecahan masalah. Siswa dapat menggunakan metode pembelajaran tersebut menyelesaikan masalah secara kreatif, kritis, logis, logis, dan kemampuan bekerjasama secara efektif serta mampu mempresentasikan ilmu yang mendasar, sehingga hal ini dapat meningkatkan kemampuan pemecahan [4].

Pada metode pembelajaran problem solving, siswa ditekankan kepada proses penyelesaian masalah yang dihadapi secara ilmiah. Tujuannya yaitu untuk meningkatkan penguasaan siswa terhadap materi, melatih ketrampilan pemecahan masalah siswa dan menunjukkan hubungan antara teori dan kenyataan kepada siswa [4].

Pembelajaran mengenai teknologi informasi telah banyak dilakukan di pendidikan menengah atas untuk mempersiapkan peserta didik menghadapi perkembangan teknologi informasi. Penerapan teknologi informasi di berbagai bidang sesungguhnya memerlukan kemampuan berpikir komputasional yang menjadi populer dalam beberapa tahun terakhir ini menjadi kemampuan yang mendasar yang seyogyanya dimiliki oleh setiap insan dalam era digital ini. Menurut [5], kemampuan berpikir komputasional adalah proses berpikir dalam melakukan formulasi persoalan dan solusinya sehingga solusi dapat dinyatakan dalam suatu bentuk yang dapat dikerjakan secara efektif oleh manusia atau mesin. Berpikir komputasional adalah kemampuan dasar yang diperlukan setiap orang, bukan hanya ilmuwan komputer. Selain kemampuan membaca, menulis, dan aritmatika, kita juga perlu menambahkan kemampuan berpikir komputasional kepada seorang anak untuk mengasah kemampuan analisisnya [5].

Sebagai salah satu butir Tri Dharma perguruan tinggi, sudah selayaknya Universitas Dian Nuswantoro memberikan sumbangsih kepada masyarakat melalui program pengabdian seperti pelatihan ini.

\section{METODE PELAKSANAAN}

Pengabdian masayarakat program Ipteks bagi Masyarakat (IbM) ini dilaksanakan dengan metode problem solving dengan menyelesaikan berbagai soal dengan pendekatan berpikir komputasi. Tempat yang digunakan dalam kegiatan ini adalah ruang kuliah di gedung G lantai 2 UDINUS. Kegiatan inti dilaksanakan selama 1 hari, yaitu tanggal 11 November 2019.

Metode yang akan digunakan dalam kegiatan ini adalah metode ceramah, praktek dan diskusi interaktif dengan cara memberikan pelatihan dan pendampingan kepada siswa-siswi dan guru pendamping dari SMA Institut Indonesia Semarang.

Pelaksanaan kegiatan pengabdian akan dilakukan dalam beberapa tahap, meliputi: 


\subsection{Tahap Persiapan}

Tahap persiapan yang dilakukan dalam melaksanakan kegiatan ini meliputi:

a. Pembuatan proposal kegiatan pengabdian dan menyelesaikan administrasi perijinan/surat kerjasama dengan mitra SMA Institut Indonesia Semarang.

b. Diskusi antara tim pengabdian dengan pihak SMA Institut Indonesia Semarang, mengenai waktu, tempat, sarana prasarana pelaksanaan pelatihan dan partisipan yang dipilih untuk mengikuti pelatihan ini.

c. Persiapan soal, sistem, dan materi pelatihan.

d. Sosialisasi dan korespondensi dengan pihak SMA Institut Indonesia Semarang.

\subsection{Tahap Pelaksanaan}

a. Pelaksanaan kegiatan ini menggunakan beberapa langkah, yaitu:

b. Melakukan koordinasi dengan pimpinan SMA Institut Indonesia Semarang selaku penanggung jawab, agar pengabdian masyarakat berjalan tertib dan lancar.

c. Menentukan waktu dan tempat penyelenggaran pelatihan.

d. Perencanaan materi pelatihan yang disesuaikan kebutuhan partisipan.

e. Menentukan narasumber.

f. Membuat undangan bagi mitra. Undangan hadir memberikan informasi tempat dan waktu pelaksanaan kegiatan serta agenda kegiatan.

g. Menyiapkan sarana dan prasarana kegiatan, seperti laptop dan laboratorium.

h. Melakukan pengarsipan kegiatan dan pengarsipan laporannya.

i. Administrasi yang meliputi undangan peserta, surat menyurat, dokumentasi, daftar hadir untuk diarsip dan untuk pembuatan pelaporan.

j. Menyiapkan tim untuk konsultasi. Dilakukan guna ada permasalahan-permasalahan yang dimungkinkan muncul pada saat pengabdian masyarakat dilaksanakan.

\section{HASIL DAN PEMBAHASAN}

Kegiatan mula-mula diawali dengan registrasi peserta dan pendamping sebelum acara dimulai. Hal ini dilakukan untuk melakukan pendataan sekaligus pencatatan identitas, termasuk untuk menyiapkan sertifikat. Mengingat peserta yang hadir juga berasal dari sekolah-sekolah yang berbeda, maka pembagian kelompok dilakukan.

Setelah memasuki ruangan, peserta diberikan penjelasan sekilas mengenai teknis pelaksanaan Bebras Challenge yang dilaksanakan.

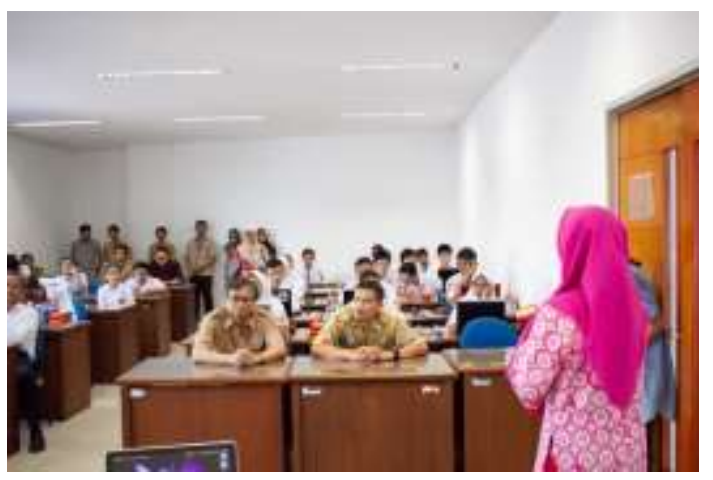

Gambar 1 Penjelasan Pelaksanaan Bebras Challenge

Adalah portal dengan alamat https://olympia.id/ yang digunakan peserta login ke dalam sistem, untuk memulai tantangan. 


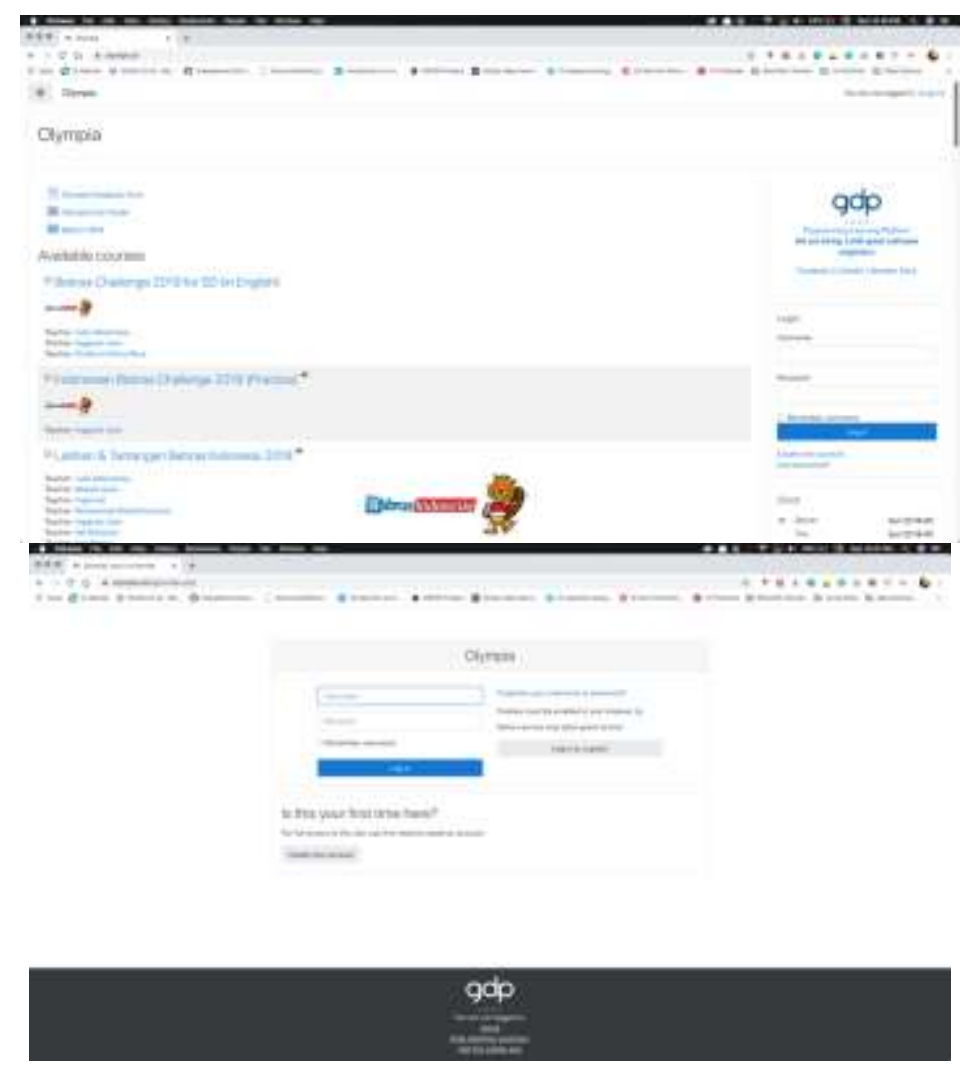

Gambar 2 Penjelasan Pelaksanaan Bebras Challenge

Apabila peserta berhasil masuk ke portal, maka terdapat pilihan untuk langsung memulai tantangan atau latihan terlebih dahulu. Adapun peserta yang mengikuti, diminta untuk melakukan latihan agar terbiasa dengan lingkungan dan suasana yang sesungguhnya.

Hasil Bebras Challenge tidak diumumkan langsung setelah acara selesai, melainkan menunggu hasil rekap dari panitia pusat. Beberapa hari kemudian, pengumuman dipublikasikan pada laman bebras.or id, dengan judul "Pengumuman Hasil Bebras Indonesia Challenge 2019". Sayangnya, dari peserta yang berasal dari sekolah mitra yaitu SMA Institut Indonesia Semarang belum ada yang berhasil membawa gelar juara. Meski demikian, keikutsertaan siswa kali ini layak diapresiasi. Karena setidaknya peserta pengabdian masyarakat mendapatkan pengalaman yang berharga, serta memiliki pengetahuan yang lebih terkait pemecahan masalah dengan pendekatan problem solving melalui computational thinking.

Bebras Challenge adalah agenda rutin tahunan, dan peserta yang belum lulus bisa mengikuti lagi pada periode selanjutnya. Dengan banyak latihan, bukan tidak mungkin, hasil lebih baik akan diraih oleh mitra dengan memperbanyak latihan dan selalu memotivasi diri.

Data yang diperoleh, pada tahun 2019 kemarin terdapat peningkatan tingkat partisipasi masyarakat pada kegiatan ini. Tercatat total ada 166 peserta yang ikut terdiri dari 14 siswa SD/Siaga, 46 siswa SMP/Penggalang, dan 106 siswa SMA/Penegak. Sedangkan tahun 2018 hanya ada 101 peserte secara keseluruhan, terdiri dari SD/Siaga sejumlah 79 siswa, dan SMP/Penggalang 22 siswa. Sementara itu untuk tingkat SMA tidak ada keikutsertaan.

Terlaksananya pengabdian ini berkat kerja sama antara tim pengabdian kepada masyarakat dari Udinus dan pihak mitra SMA Institut Indonesia Semarang. Berikut adalah adalah contoh dokumentasi dalam bentuk foto. 


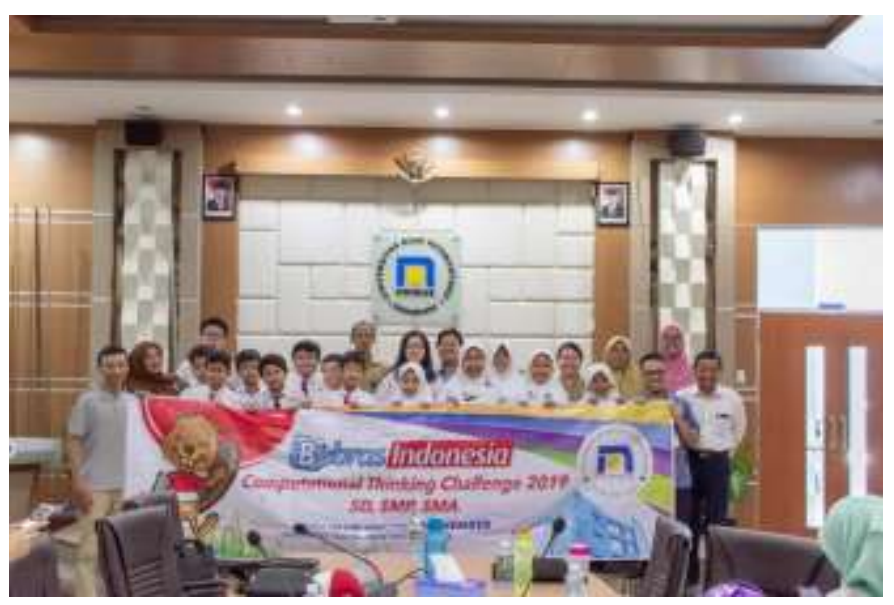

Gambar 3 Dokumentasi antara peserta dan tim pengabdian

\section{KESIMPULAN}

Terdapat tiga kesimpulan yang dapat diambil dari kegiatan ini. Pertama, peserta dari mitra pengabdian kepada masyarakat mengenal metode pemecahan masalah menggunakan pendekatan computational thinking. Kedua, peserta dari mitra pengabdian kepada masyarakat termotivasi untuk menyelesaikan soal-soal yang memerlukan kemampuan berpikir secara komputasional. Ketiga, peserta dari mitra pengabdian kepada masyarakat dapat menerapkan ilmu yang diperoleh, untuk menyelesaikan masalah sehari-hari. Kesimpulan tersebut sekaligus menunjukkan dampak pengabdian kepada masyarakat secara langsung kepada peserta kegiatan.

\section{SARAN}

Adapun saran yang diberikan terhadap kegiatan ini adalah:

a. Memperbanyak tenaga untuk membantu pelatihan kegiatan, mengingat antusias peserta yang besar, dan jumlah sumber daya yang terbatas

b. Waktu pelaksanaan perlu dikelola lebih baik, untuk meningkatkan kemampuan peserta mencerna dan memahami materi yang diberikan.

c. Materi pengabdian kepada masyarakat dapat ditambahkan dan dikembangkan, untuk proses lebih lanjut.

\section{UCAPAN TERIMA KASIH}

Penulis menyampaikan terima kasih kepada LPPM Universitas Dian Nuswantoro serta Dinas Pendidikan Kota Semarang dan pihak SMA Institut Indonesia Semarang yang telah memberi dukungan terhadap kegiatan pengabdian kepada masyarakat ini.

\section{DAFTAR PUSTAKA}

[1] Andini, Lina; Nuryono, Wiryo. (2016). Pengembangan Buku Panduan Kemampuan Problem Solving untuk Siswa Sekolah Menengah Pertama. Jurnal BK UNESA vol. 6 no. 1 pp. 19

[2] Hartini. (2017). Perkembangan Fisik Dan Body Image Remaja. Islamic Counseling vol. 1 no. 2 pp. $27-54$ 
[3] Jannah, Miftahul. (2016). Remaja dan Tugas-tugas Perkembangannya Dalam Islam. Jurnal Psikoislamedia vol. 1 no. 1 pp. 243-256

[4] Husna; Burais, Fona Fitry. (2018). Penggunaan Problem Solving untuk Meningkatkan Kemampuan Pemecahan Masalah Matematis Siswa SMA. Jurnal Peluang vol. 6 no. 2 pp. 1-7

[5] Ayub, Mewati; Wijanto, Maresha Caroline; Senjaya, Wenny Franciska; Karnalim, Oscar; Kandaga, Tjatur; Witono, Timotius; Edi, Doro; Sujadi, Ferdian Sendy; Kartawihardja, Djoni Setiawan; Santosa, Sulaeman ; Gantini, Tiur. (2017). Edukasi Berpikir Komputasional melalui Pelatihan Guru dan Tantangan Bebras untuk Siswa di Bandung pada Tahun 2016-2017. Seminar Nasional Pengabdian Kepada Masyarakat vol. 2 no. 2 pp. $12-18$ 